\section{Isolation of Sclerosporin, a Sporogenic Substance, from Sclerotinia fructicola}

\section{Masato Katayama and Shingo Marumo \\ Department of Agricultural Chemistry, Nagoya University, Chikusa-ku, Nagoya 464 \\ Received December 19, 1977}

Sclerotinia fructicola, a pathogenic brown rot fungus of stone fruits, has been known to produce abundant asexual arthrospores when grown in darkness, whereas poorly or not at all under illumination of light. ${ }^{13}$ We found that the dark-induced sporulation of this fungus was attributed to production of a sporogenic substance in the mycelia cultured in darkness. We wish now to describe the isolation of this active metabolite, named sclerosporin, from $S$. fructicola, and its sporogenic activity also. Sclerosporin was able to induce sporulation on the mycelia grown under illumination of light.

S. fructicola was cultured on potato agar medium with $2 \%$ sucrose in darkness at $30^{\circ} \mathrm{C}$ for a week. The full-grown mycelia bearing abundant arthrospores as well as the cultured nutrient agar was macerated with acetone, and the acetone extracts were condensed below $40^{\circ} \mathrm{C}$ to the aqueous residue, which was extracted with ethyl acetate at $\mathrm{pH}$ 7.0. Since the activity was quite labile in alkaline solution, the isolation procedure was conducted in neutral and acidic conditions. The ethyl acetate extracts were subjected to preparative thin-layer chromatography (ptlc) on Kiesel gel $60 \mathrm{PF}_{254}$ (solvent; ethyl acetate: $n$-hexane $=7: 3$ ), and the active $R f 0.6 \sim 0.8$ zone was scraped out. The eluate from the plate was then subjected once more to the similar ptlc, by changing the solvent composition into a 3:7. The active fraction thus obtained contained ergosterol, which was removed by recrystallization from ethyl acetate- $n$-hexane (1:9). The final purification was carried out by high performance liquid chromatography (Lichrosorb RP-2, $\phi 4 \mathrm{~mm} \times 250 \mathrm{~mm}$, solvent: dioxane- $\mathrm{H}_{2} \mathrm{O}(6: 4)$, pressure: $80 \mathrm{~kg} / \mathrm{cm}^{2}$, a flow rate: $1.0 \mathrm{ml} / \mathrm{min}$, detector: UV $234 \mathrm{~nm}$ ). The active compound was eluted (retention time: $6.0 \mathrm{~min}$ ) in pure form (yield $182 \mu \mathrm{g}$ from 4 liters of the cultured materials).

Sclerosporin had the molecular formula $\mathrm{C}_{15} \mathrm{H}_{22} \mathrm{O}_{2}$ (observed m/e 234.1647; calcd 234.1620), and showed, in the mass spectrum (Fig. 1), intense fragment ions at $m / e 191$ $\left(\mathrm{C}_{12} \mathrm{H}_{15} \mathrm{O}_{2}\right), 173\left(\mathrm{C}_{12} \mathrm{H}_{13} \mathrm{O}\right), 135\left(\mathrm{C}_{8} \mathrm{H}_{7} \mathrm{O}_{2}\right)$ and $91\left(\mathrm{C}_{7} \mathrm{H}_{7}\right)$. These data suggested, with other preliminary evidence, that the compound should be a metabolite hitherto unreported, belonging to a bicyclic sesquiterpenoid class with a seven-membered ring and an isopropyl group.

The sporogenic activity of sclerosporin was measured on $S$. fructicola. The bioassayed results are shown in Table I. A test solution

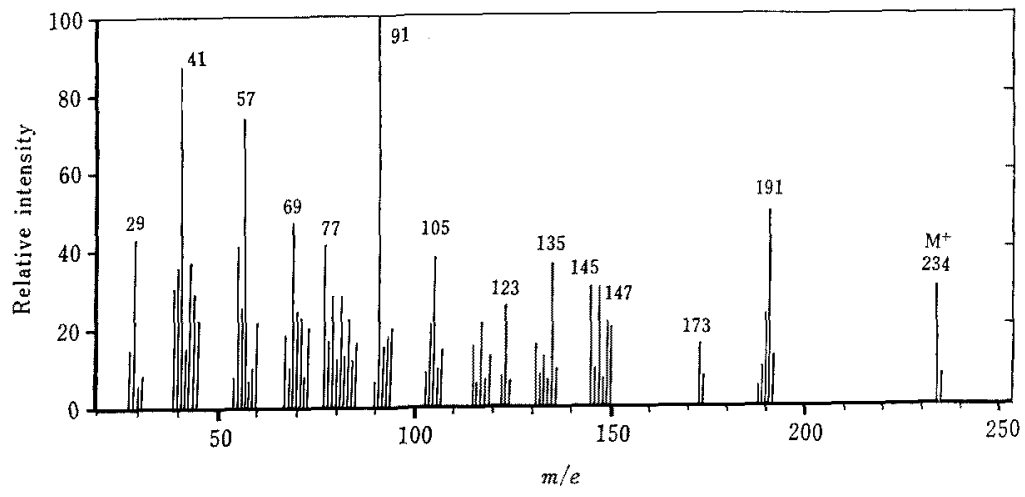

FIG. 1. The Mass Spectrum of Sclerosporin. 
TABle I. Sporogenic Activity of SCLEROSPORIN ON $S$. fructicola

\begin{tabular}{ccc}
$\begin{array}{c}\text { dose }(\mu \mathrm{g}) / \text { agar } \\
\text { medium }(1 \mathrm{~m})\end{array}$ & $\begin{array}{c}\text { Light } \\
\text { conditions }\end{array}$ & $\begin{array}{c}\text { Numbers of } \\
\text { arthrospores }(\%)\end{array}$ \\
\hline 0 & dark & $1218(100)$ \\
0 & light & $90(7)$ \\
\hline 0.0005 & light & $110(9)$ \\
0.001 & - & $181(15)$ \\
0.005 & - & $157(13)$ \\
0.01 & - & $195(16)$ \\
0.05 & - & $257(22)$ \\
0.1 & - & $367(30)$ \\
0.5 & - & $309(25)$ \\
1 & - & $533(44)$ \\
5 & - & $962(79)$ \\
\hline
\end{tabular}

dissolved in ethyl acetate $(30 \mu \mathrm{l})$ was added onto a slant containing a potato-sucrose medium $(5 \mathrm{ml})$. The slant inoculated with the fungus was then incubated under a fluorescence lamp (Toshiba FL 40S.D/NL, 7500 lux) at $25^{\circ} \mathrm{C}$. As a control, the slants to which only ethyl acetate was added before inoculation were incubated either in darkness or under a fluorescence lamp. After a $72 \mathrm{hr}$ incubation, the arthrospores produced were counted in the area $(5 \mathrm{~mm} \times 5 \mathrm{~mm})$ collected near the top of the slant culture. Sclerosporin exhibited weak but significant sporogenic activity at $0.001\left(4 \times 10^{-9} \mathrm{M}\right) \sim 0.005 \mathrm{ppm}\left(2 \times 10^{-8} \mathrm{M}\right)$, and the activity enhanced as the amount of the sample increased. At the maximum concentration $\left(5 \mathrm{ppm}\right.$ or $2 \times 10^{-5} \mathrm{M}$ ) tested, the $79 \%$ production of arthrospores compared with those in darkness was observed.

Recently, a photo-sporogenesis in fungi has been extensively investigated, ${ }^{2}$ including chemical studies on a photoreceptor pigment ${ }^{3)}$ and substances $^{4}$ effective for sporulation. Our present finding of sclerosporin is the first isolation of a sporogenic substance from the fungi which sporulated under the dark condition. Structural elucidation of sclerosporin using ultramicro-techniques is now in progress.

Acknowledgement. The authors wish to thank the Ministry of Education for financial support given on this work.

\section{REFERENCES}

1) M. P. Hall, Ann. Bot., 47, 543 (1933).

2) C. M. Leach, "Methods in Microbiology," Vol. IV, ed. by C. Booth, Academic Press Inc., London and New York, 1971, pp. 609 664.

3) a) C. M. Leach and E. J. Trione, Plant Physiol., 40, 808 (1965); b) J. Favre-Bonvin, N. Arpin and C. Brevard, Can. J. Chem., 54, 1105 (1976); c) N. Arpin, J. Favre-Bonvin and S. Thivend, Tetrahedron Lett., 1977, 819.

4) a) H. Hattori and S. Marumo, Abstracts of papers, 48th Ann. Meeting of Japan Agric. Chem. Soc., 1973 , p. 353 ; b) S. B. Hyeon, A. Suzuki and S. Tamura, Agric. Biol. Chem., 40, 1263 (1976). 